\title{
Identifikasi Pemeliharaan Vertical Garden di Fairmont Sanur Beach Bali
}

\author{
Ni Luh Putu Ari Radinasuari ${ }^{1}$, Cokorda Gede Alit Semarajaya ${ }^{1 *}$, I Made Sukewijaya ${ }^{2}$ \\ 1. Prodi Arsitektur Lanskap, Fakultas Pertanian, Universitas Udayana, Indonesia 80232 \\ 2. Prodi Agroekoteknologi, Fakultas Pertanian, Universitas Udayana, Indonesia 80232 \\ *E-mail: coksemarajaya@unud.ac.id
}

\begin{abstract}
Maintenance Identification on Vertical Garden at Fairmont Sanur Beach Bali. Fairmont Sanur Beach Bali has a vertical garden with an area of $10 \mathrm{~m} \times 4 \mathrm{~m}$. The Hotel is able to maintain the plant condition. The purpose of this research is to identify the vertical garden maintenance system at the Fairmont Sanur Beach Bali. The research method uses survey and literature study methods. Data collection techniques are observation, interview, and literature study. Data analysis methods with descriptive methods and scoring tables. The results about the identification of vertical garden maintenance systems consist of watering, water disposal system, trimming, fertilizing, replanting plants, media replacement, sanitation, pest and disease control. Watering in 2 hours creating high humidity in the media. The volume of water released is not fully experienced evapotranspiration. The planting media do not experience drought during the day, so the plants keep fresh. In the calculation of plant suitability values, the corresponding values are Hemigraphis alternata. Plants with adequate value are Epipremnum aureum, Asparagus densiflorus, Ananas bracteatus tricolor, Schefflera Arboricola, and Portulaca grandiflora. In the maintenance process requires a fertigation system to facilitate fertilization. The use of automated systems such as timmers will simplify the maintenance and a more scheduled.
\end{abstract}

Keywords: identification, maintenance, vertical garden

\section{Pendahuluan}

Vertical garden atau taman tegak adalah tanaman dan elemen tanam lainnya yang disusun sedemikian rupa dalam bidang yang tegak lurus (Budiarto, 2013). Tujuan utama dari vertical garden adalah menciptakan efisiensi lahan (Ferniasari, 2011). Permasalahan umumnya dalam pemeliharaan vertical garden yaitu kerusakan tanaman karena kurangnya pemahaman akan sistem pemeliharaan yang sesuai. Salah satu hotel di Bali yang memiliki vertical garden adalah Fairmont Sanur Beach Bali. Vertical garden di Fairmont Sanur Beach Bali seluas $10 \mathrm{~m} \times 4 \mathrm{~m}$ yang terletak pada area menuju lobi hotel. Pemasangannya pada tembok bangunan bertujuan untuk meningkatkan nilai keindahan. Hotel tersebut mampu mempertahankan kondisi tanaman pada vertical garden agar tidak rusak. Oleh karena itu penelitian ini bertujuan untuk mengindentifikasi sistem pemeliharaan vertical garden di Fairmont Sanur Beach Bali. Hasil identifikasi tersebut dapat menjadi referensi dalam proses pemeliharaan vertical garden dan memberikan rekomendasi terkait permasalahan yang dihadapi di Fairmont Sanur Beach Bali.

\section{Metode}

\subsection{Waktu dan Lokasi}

Penelitian ini dilakukan pada Fairmont Sanur Beach Bali, Jalan Kusuma Sari No. 8, Sanur, Denpasar Selatan, Kota Denpasar. Penelitian dilakukan selama 6 bulan yakni bulan April 2019 hingga September 2019. Peta lokasi penelitian dapat dilihat pada gambar 1. 


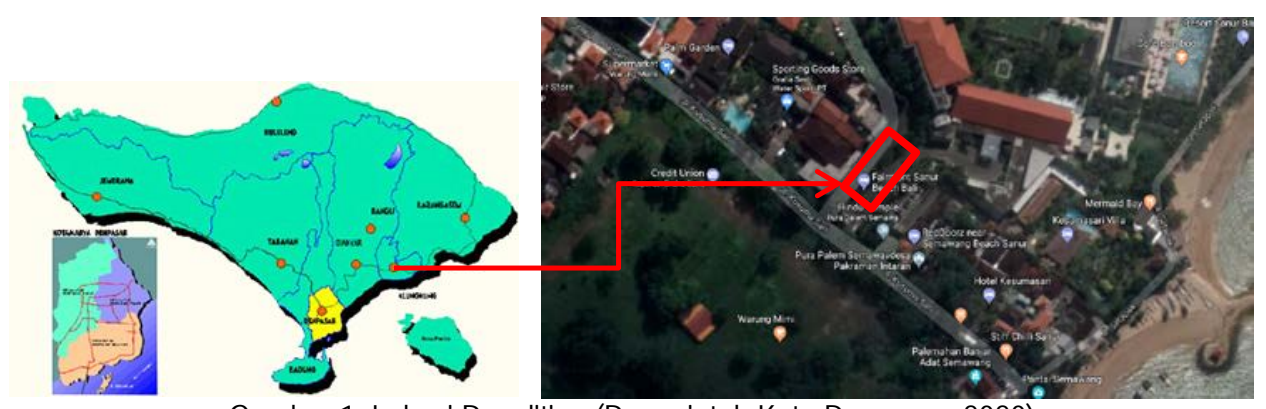

Gambar 1. Lokasi Penelitian (Pemerintah Kota Denpasar, 2020)

\section{$2.2 \quad$ Alat dan Bahan}

Penelitian ini menggunakan alat berupa perangkat keras (hardware) seperti kamera berfungsi sebagai pengambil gambar, laptop sebagai pengolah data, dan meteran sebagai pengukur. Serta perangkat lunak (software) seperti MS Word 2010 sebagai pengolah kata, MS Excel 2010 sebagai pengolah angka, dan Photoshop CC 2019 sebagai pengolah gambar.

\subsection{Metode Penelitian}

Metode penelitian menggunakan metode survei dan studi pustaka. Metode pengumpulan data dengan observasi langsung tehadap kondisi objek penelitian, wawancara dengan pihak pengelola. Studi pustaka berupa literatur yang berkaitan yaitu dengan buku dan dokumen.

\subsection{Metode Analisis Data}

Metode analisis data menggunakan deskriptif dan tabel skoring kesesuaian jenis tanaman. Proses analisis kesesuaian tanaman menggunakan tabel skoring dengan memberikan bobot angka pada aspek syarat dan daya tumbuh tanaman berdasarkan pustaka. Penelitian ini akan diperoleh gambaran tentang kegiatan pemeliharaan vertical garden.

\section{Hasil dan Pembahasan}

\subsection{Identifikasi Kondisi Fisik}

Identifikasi kondisi fisik bertujuan untuk mengetahui kondisi lingkungan yang menunjang keberlanjutan vertical garden. Indikator yang diteliti pada kondisi fisik ini adalah letak dan luas, hidrologi dan iklim, sistem pemasangan, media tanam dan desain.

\subsubsection{Letak dan Luas}

Fairmont Sanur Beach Bali beralamat di Jalan Kusuma Sari No. 8, Kelurahan Sanur, Kecamatan Denpasar Selatan, Kota Denpasar. Luas vertical garden pada Fairmont Sanur Beach Bali sebesar $10 \mathrm{~m} \times 4 \mathrm{~m}$, dan terletak pada lobi hotel, sehingga dapat diakses oleh seluruh pengunjung.

\subsubsection{Hidrologi dan Iklim}

Sumber air yang digunakan untuk kepentingan taman dan vertical garden berasal dari PDAM (Perusahaan Daerah Air Minum) dan air daur ulang limbah hotel dengan sistem STP (sewage treatment plant). Sistem pengelolaan air limbah cair pada hotel Fairmont Sanur Beach Bali menggunakan metode Kombinasi Biosystem dan Active Sludge System. Berdasarkan data BMKG (Badan Meteorologi, Klimatologi, dan Geofisika) pada pos Desa Pedungan, Kecamatan Denpasar Selatan menyatakan suhu udara rata-rata pada tahun 2009 hingga 2018 sebesar $27,7^{\circ} \mathrm{C}$. Lama penyinaran matahari rata-rata pada tahun 2009 hingga 2018 sebesar 67,4\%. Kelembapan udara rata-rata pada tahun 2009 hingga 2018 sebesar 78,8\%.

\subsubsection{Sistem Pemasangan Vertical Garden}

Vertical garden pada Faimont Sanur Beach Bali termasuk kedalam kategori Living walls karena menggunakan instalasi pemasangan sistem modular dengan VGM (vertical green module). Modul VGM yang digunakan memiliki 16 lubang dalam 1 bingkai dengan ukuran $50 \mathrm{~cm} \times 50 \mathrm{~cm}$. Berbahan dasar plastik sehingga 
tidak mudah rusak dan lebih kokoh karena tahan terhadap hujan atau paparan cahaya matahari. Pemasangan tanaman dan media tanam pada VGM dengan cara dimasukkan kedalam lubang tanam pada bingkai VGM. Sistem pemasangannya yang seperti puzzle sehingga memudahkan untuk membentuk pola desain yang diinginkan. Pada vertical garden di Fairmont Sanur Beach Bali, VGM terpasang pada tembok dengan struktur peyangga menggunakan besi (Gambar 2).

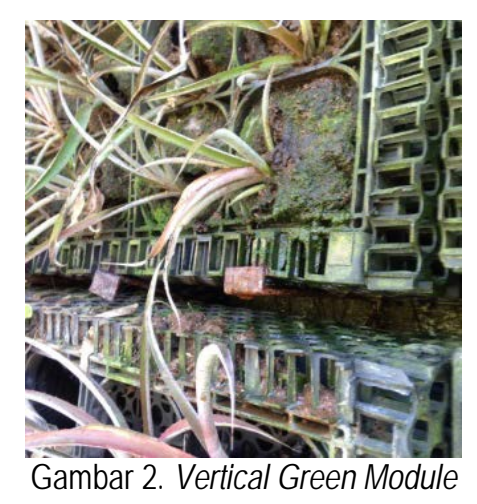

\subsubsection{Media Tanam}

Pada vertical garden di Fairmont Sanur Beach Bali menggunakan media tanam yang berbeda pada setiap jenis tanamannya. Hal tesebut disesuaikan dengan jenis perakaran, dan daya tampung air. Berikut merupakan tabel penggunaan media tanam dan spesies tanaman yang dilakukan pada Fairmont Sanur Beach Bali.

Tabel 1. Penggunaan Media Tanam Vertical Garden di Fairmont Sanur Beach Bali

\begin{tabular}{cll}
\hline No. & \multicolumn{1}{c}{ Spesies Tanaman } & \multicolumn{1}{c}{ Media Tanam } \\
\hline 1 & Ananas bracteatus tricolor & Spons dan Geotextile \\
2 & Asparagus densiflorus & Tanah dan Geotextile \\
3 & Epipremnum aureum & Tanah dan Geotextile \\
4 & Hemigraphis alternata & Tanah dan Geotextile \\
5 & Portulaca grandiflora & Spons dan Geotextile \\
6 & Schefflera arboricola & Tanah dan Geotextile \\
\hline
\end{tabular}

Tanaman Ananas bracteatus tricolor dan Portulaca grandiflora menggunakan media tanam spons. Media spons memiliki daya serap air yang tinggi sehingga sesuai dengan tanaman yang memiliki kebutuhan penyiraman intensif. Spons tersebut dimasukkan kedalam polybag agar tidak mudah rusak atau lapuk. Polybag dibungkus dengan geotextile sebagai penahan bentuk agar ukurannya sesuai dengan lubang pada modul dan memberikan keseragaman warna pada media tanam. Media tanam tanah memerlukan geotextile untuk menjaga bentuk tanah agar tetap menutupi akar tanaman.

\subsubsection{Desain}

Tujuan pemasangan vertical garden untuk meningkatkan nilai estetika pada lobi hotel dengan memberikan kesan hijau dan unik pada dinding (Gambar 3). Pemilihan tanaman yang digunakan berdasarkan karakteristik tanaman yang sesuai dengan keadaan lingkungan vertical garden. 


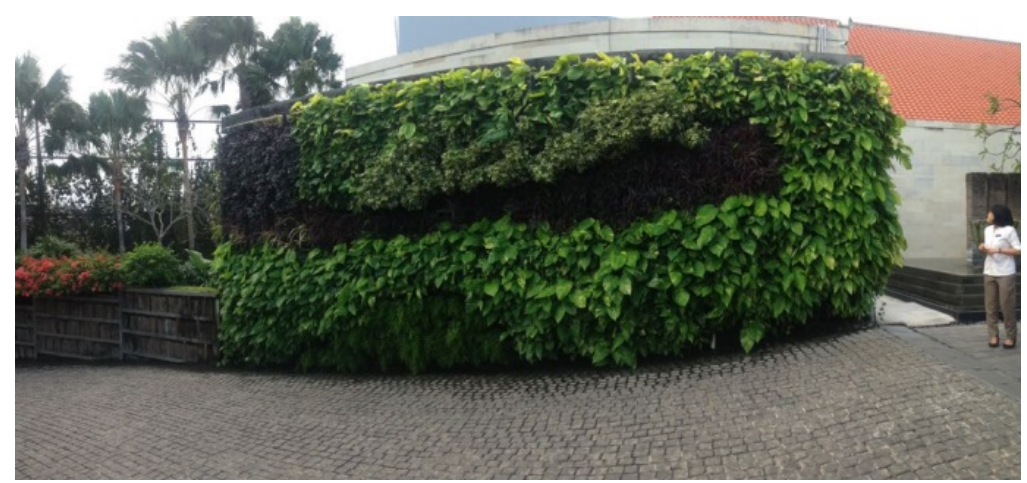

Gambar 3. Vertical Garden Pada Lobi Hotel

\subsubsection{Pola Penanaman}

Tanaman yang digunakan pada vertical garden di Fairmont Sanur Beach Bali beberapa kali mengalami perubahan. Hal tersebut dapat terjadi karena ketidaksesuaian syarat tumbuh tanaman dengan lingkungan pada vertical garden. Sehingga perubahan tanaman dilakukan untuk menanggulangi kerusakan yang terjadi agar vertical garden tetap terlihat menarik bagi pengunjung hotel. Selama masa penelitian, ditemukan beberapa perubahan jenis tanaman (Gambar 4).

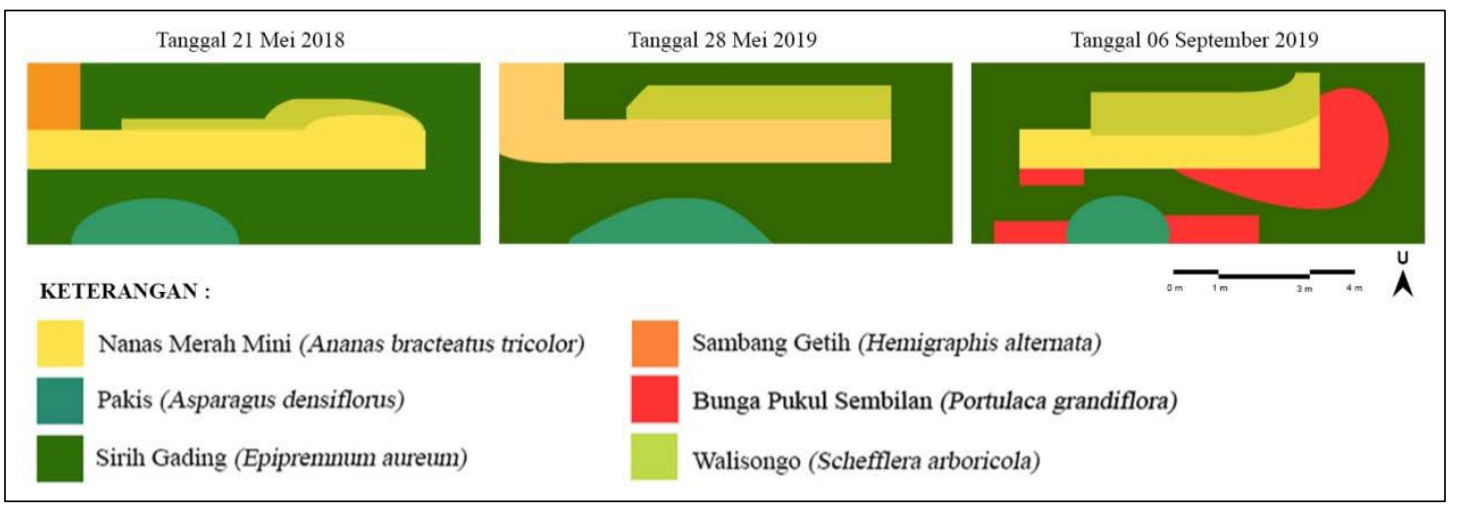

Gambar 4. Pola Perubahan Tanaman Vertical Garden

Pada gambar diatas menunjukkan bahwa keberadaan tanaman Asparagus densiflorus semakin mengecil akibat kerontokkan pada daun sehingga posisinya terus digantikan dengan tanaman lain. Hal tersebut karena kebutuhan cahaya tanaman Asparagus densiflorus adalah seminaungan (tanaman yang tidak terkena sinar matahari secara lansung), sedangkan pada vertical garden di Fairmont Sanur Beach Bali membutuhkan tanaman dengan kebutuhan cahaya penuh dan langsung.

\subsection{Identifikasi Biofisik}

Identifkasi biofisik bertujuan untuk mengetahui aspek biofisik pada vertical garden. Komponen yang diidentifikasi berupa inventarisasi jenis tanaman, syarat dan daya tumbuh tanaman, serta kesesuaian tanaman.

\subsubsection{Inventarisasi Tanaman}

Vertical garden di Fairmont Sanur Beach Bali menggunakan tanaman yang beragam dengan kebutuhan dan karakteristik yang berbeda. Daftar tanaman yang digunakan pada vertical garden dapat dilihat pada Tabel 2 sebagai berikut: 
Tabel 2. Daftar Tanaman pada Vertical Garden

\begin{tabular}{ccc}
\hline No. Nama Latin & Nanas merah mini \\
\hline $1 \quad$ Ananas bracteatus tricolor & Asparagus densiflorus & Pakis \\
3 & Epipremnum aureum & Sirih gading \\
4 & Hemigraphis alternata & Sambang getih \\
5 & Schefflera arboricola & \\
& &
\end{tabular}

Tanaman-tanaman tersebut memiliki syarat tumbuh dan daya tumbuh yang berbeda. Pemilihan tanaman tersebut oleh pengelola berdasarkan kemampuan tumbuh dan kemudahan dalam proses perbanyakan tanaman sehingga dapat menekan biaya pemeliharaan.

3.2.2 Syarat dan Daya Tumbuh Tanaman

Tanaman dengan syarat dan daya tumbuh yang tidak sesuai dengan lingkungan tanamnya akan rentan terhadap kerusakan jika tidak diimbangi dengan pemeliharaan yang tepat. Syarat dan daya tumbuh tanaman pada vertical garden di Fairmont Sanur Beach Bali dapat dilihat pada tabel 3.

Tabel 3. Syarat dan Daya Tumbuh Tanaman

\begin{tabular}{|c|c|c|c|c|c|}
\hline No. & Spesies Tanaman & Kebutuhan Cahaya & Kelembapan & $\begin{array}{l}\text { Kebutuhan } \\
\text { Penyiraman }\end{array}$ & $\begin{array}{c}\text { Kecepatan } \\
\text { Tumbuh }\end{array}$ \\
\hline 1 & $\begin{array}{l}\text { Ananas bracteatus } \\
\text { tricolor }\end{array}$ & $\begin{array}{l}\text { Penuh dan langsung, } \\
\text { seminaungan }\end{array}$ & Sedang & Intensif & Cepat \\
\hline 2 & Asparagus densiflorus & Seminaungan & Sedang & Semiintensif & Cepat \\
\hline 3 & Epipremnum aureum & $\begin{array}{l}\text { Penuh dan langsung, } \\
\text { seminaungan }\end{array}$ & Sedang & Intensif & Sedang \\
\hline
\end{tabular}




\begin{tabular}{ccccll}
\hline No. & Spesies Tanaman & Kebutuhan Cahaya & Kelembapan & $\begin{array}{l}\text { Kebutuhan } \\
\text { Penyiraman }\end{array}$ & $\begin{array}{c}\text { Kecepatan } \\
\text { Tumbuh }\end{array}$ \\
\hline 4 & Hemigraphis alternata & Penuh dan langsung & Sedang & Semiintensif & Cepat \\
5 & Portulaca grandiflora & Penuh dan langsung & Tinggi & Intensif & Cepat \\
6 & Schefflera arboricola & Penuh dan langsung & Sedang & Intensif & Sedang \\
\hline
\end{tabular}

Sumber: Lestari dan Kencana (2015)

Kebutuhan cahaya matahari penuh dan langsung adalah tanaman memerlukan cahaya maksimal sepanjang hari, sedangkan seminaungan adalah tanaman memerlukan cahaya yang tersaring atau tidak terkena matahari secara langsung. Kelembapan sedang berada pada kisaran 40\% hingga 60\%, kelembapan tinggi berada pada kisaran 60\% hingga 100\% umumnya kisaran kelembapan udara pada daerah hutan hujan tropis (Lestari dan Kencana, 2015).

\subsubsection{Kesesuaian Tanaman}

Kesesuaian jenis tanaman berpengaruh terhadap keberlanjutan pemeliharaan vertical garden, tanaman dengan nilai yang sesuai dan cukup sesuai sangat direkomendasikan untuk dipertahankan, sedangkan tanaman yang tidak sesuai membutuhkan pemeliharaan yang lebih intensif. Nilai kesesuaian tanaman vertical garden di Fairmont Sanur Beach Bali dapat dilihat pada Tabel 4.

Tabel 4. Kesesuaian Tanaman Pada Vertical Garden

\begin{tabular}{clccccc}
\hline No. & Spesies Tanaman & $\begin{array}{c}\text { Kebutuhan } \\
\text { Cahaya }\end{array}$ & Kelembapan & $\begin{array}{c}\text { Kebutuhan } \\
\text { Penyiraman }\end{array}$ & $\begin{array}{c}\text { Kecepatan } \\
\text { Tumbuh }\end{array}$ & $\begin{array}{c}\text { Jumlah } \\
\text { Nilai }\end{array}$ \\
\hline 1 & $\begin{array}{l}\text { Ananas bracteatus } \\
\text { tricolor }\end{array}$ & 150 & 40 & 20 & 10 & 220 \\
2 & Asparagus densiflorus & 100 & 40 & 40 & 10 & 190 \\
3 & Epipremnum aureum & 150 & 40 & 20 & 20 & 230 \\
4 & Hemigraphis alternata & 150 & 40 & 40 & 10 & 240 \\
5 & Portulaca grandiflora & 150 & 20 & 20 & 10 & 200 \\
6 & Schefflera arboricola & 150 & 40 & 20 & 20 & 230 \\
\hline
\end{tabular}

Jumlah nilai sesuai berada pada angka 234 - 300, cukup sesuai berada pada angka 167 - 233, dan tidak sesuai berada pada angka 100 - 166. Berasarkan pada nilai tersebut tanaman vertical garden di Fairmont Sanur Beach Bali yang memiliki nilai sesuai adalah tanaman Hemigraphis alternata. Tanaman dengan nilai cukup sesuai adalah Epipremnum aureum, Asparagus densiflorus, Ananas bracteatus tricolor, Schefflera arboricola, dan Portulaca grandiflora. Tanaman dengan nilai terendah adalah Asparagus densiflorus. Hal tersebut juga ditunjukan dengan berkurangnya luasan tanaman tersebut karena kerontokan daun.

\subsection{Identifikasi Sistem Pemeliharaan}

Sistem pemeliharaan pada vertical garden ataupun jenis taman lainnya merupakan hal penting yang menentukan keberlanjutan taman tesebut. Pemeliharaan vertical garden di Fairmont Sanur Beach Bali terdiri atas sistem irigasi, pemupukan, pemangkasan, pembersihan daun, pengendalian hama dan penyakit, dan penyulaman tanaman.

\subsubsection{Sistem Irigasi}

Sistem irigasi terdiri atas penyiraman dan optimalisasi pengairan. Penyiraman menggunakan proses manual dengan dua cara, yaitu membuka tutup valve/katup dan menggunakan selang (Gambar 5). Kedua cara tersebut tetap menggunakan metode irigasi tetes cascading, yaitu dengan pipa tetes yang mengalirkan air dari modul satu ke modul di bawahnya. 


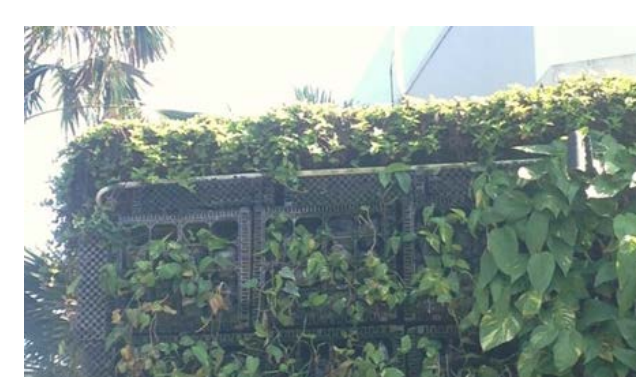

a. Penyiraman Cara Pertama

Gambar 5. Proses Penyiraman

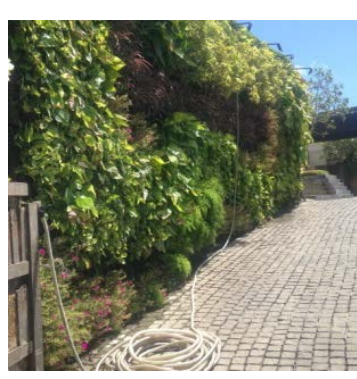

b. Penyiraman Cara Kedua

Proses penyiraman cara pertama menggunakan valve/katup sebagai pembuka dan penutup aliran air yang terhubung dengan pipa irigasi pada bagian atas vertical garden. Penyiraman cara kedua dengan menggunakan selang yang terhubung pada keran air kemudian dihubungkan dengan pipa irigasi di atas vertical garden. Penggunaan sistem penyiraman pertama atau kedua ditentukan dengan jumlah air yang tersedia. Umumnya penyiraman cara pertama lebih sering dilakukan. Sedangkan penyiraman kedua dilakukan jika air tidak mampu naik menuju pipa irigasi. Frekuensi penyiraman vertical garden yang dilakukan di Fairmont Sanur Beach Bali dapat dilihat pada Tabel 5.

Tabel 5. Frekuensi dan Durasi Penyiraman

\begin{tabular}{ccl}
\hline No. & \multicolumn{1}{c}{ Jenis Penyiraman } & \multicolumn{1}{c}{ Frekuensi dan Durasi Penyiraman } \\
\hline 1 & Penyiraman cara pertama (valve) & 2 jam (08.00-10.00) \\
2 & Penyiraman cara kedua (selang) & 2 jam (10.00-12.00), atau (18.00-20.00) \\
\hline
\end{tabular}

Penyiraman dilakukan selama 2 jam agar terciptanya kelembapan yang tinggi sehingga pada siang hari tanaman tidak mengalami dehidrasi karena penguapan. Metode tersebut berbeda dengan pedoman penyiraman vertical garden umumnya yang hanya dilakukan selama 5 menit dengan sistem irigasi tetes. Meskipun berbeda dengan pedoman, metode tersebut mampu mempertahankan kondisi tanaman agar tetap segar.

\subsubsection{Sistem Pembuangan Air}

Sistem pembuangan air pada vertical garden di Fairmont Sanur Beach Bali tidak menggunakan talang, air yang turun dari tanamanan dibiarkan mengalir pada paving hingga ke lubang drainase tanpa adanya filter khusus (Gambar 6). Pemeliharaanya berupa pembersihan lumut pada paving agar tidak licin (Gambar 7).

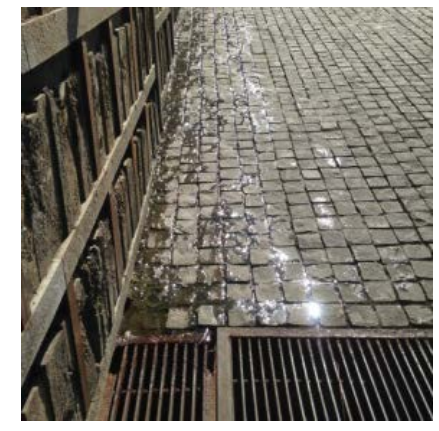

Gambar 6. Sistem Pembuangan Air

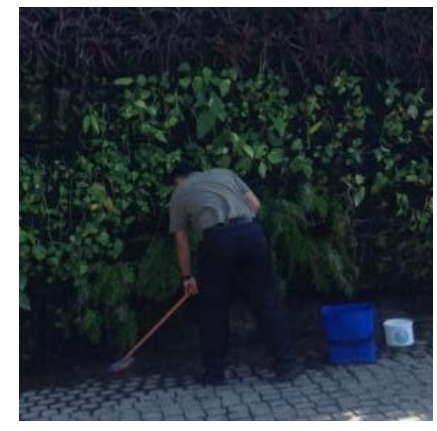

Gambar 7. Pembersihan Paving

\subsubsection{Pemupukan}

Pemupukan yang dilakukan pada vertical garden di Fairmont Sanur Beach Bali menggunakan pupuk NPK yang dicairkan, dilakukan $3-4$ bulan sekali. Pada proses pemupukan dilakukan secara manual. 


\subsubsection{Pemangkasan}

Setiap tanaman memiliki fokus pemangkasan yang berbeda, tergantung pada kecepatan tumbuh dan kebutuhan estetika. Pemangkasan yang dilakukan pada vertical garden di Fairmont Sanur Beach Bali dapat dilihat pada Tabel 6 .

Tabel 6. Pemangkasan Tanaman pada Vertical Garden

\begin{tabular}{cll}
\hline No. & Spesies Tanaman & Pemangkasan \\
\hline 1 & Epipremnum aureum & Batang \\
2 & Asparagus densiflorus & Batang \\
3 & Hemigraphis alternata & Batang \\
4 & Ananas bracteatus tricolor & Daun \\
5 & Schefflera arboricola & Akar, batang \\
6 & Portulaca grandiflora & Batang \\
\hline
\end{tabular}

Pemangkasan dilakukan secara tidak berkala, tetapi situasional yaitu ketika tanaman sudah tumbuh melebihi $20 \mathrm{~cm}$ dari permukaan vertical garden. Proses pemangkasan menggunakan gunting stek. Tanaman Schefflera arboricola secara khusus dilakukan pemangkasan akar, hal tersebut bertujuan untuk menghambat pertumbuhan tanaman.

\subsubsection{Pembersihan Daun}

Kegiatan pembersihan atau sanitasi daun dilakukan setiap hari setelah ataupun sebelum penyiraman, dengan membuang daun yang sudah menguning dan layu (Gambar 8). Pembersihan daun wajib dilakukan pada vertical garden di Fairmont Sanur Beach Bali karena letak vertical garden pada area lobi yang secara berkala dilalui oleh para pengunjung hotel.

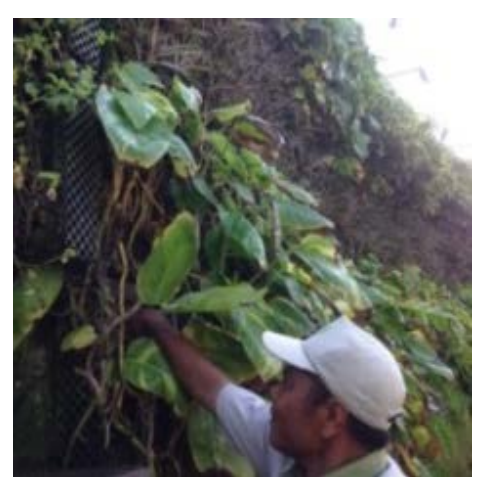

Gambar 8. Pembuangan Bagian Tanaman Layu

\subsubsection{Pengendalian Hama dan Penyakit}

Penyemprotan insektisida Diazinon untuk mengatasi hama kutu. Kegiatan tersebut dilakukan situasional ketika tanaman terserang hama. Dosis pemberian insektisida tersebut dengan mencairkan $5 \mathrm{ml}$ ke dalam 1 liter air. Penyemprotan dilakukan pada jam 6 pagi agar tidak menimbulkan bau menyengat ketika terkena matahari. Selain dilakukan penyemprotan, media tanam spons juga membantu dalam mencegah serangan penyakit karena merupakan bahan anorganik. Beberapa media tanam menunjukkan pertumbuhan jamur yang diduga merupakan jamur Rhizopus sp. (Gambar 9). Terlihat dari persebaran bercak putih pada beberapa bagian media. Pihak pengelola mengatasi hal tersebut dengan melakukan penyulaman tanaman dan pergantian media tanam guna mengurangi persebaran pertumbuhan jamur. 


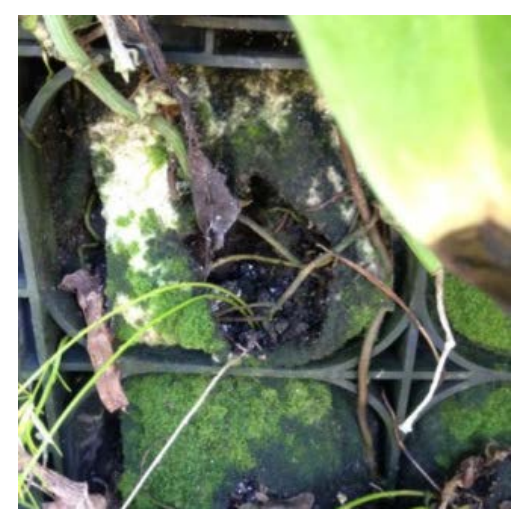

Gambar 9. Jamur Pada Media Tanam

\subsubsection{Penyulaman Tanaman}

Penyulaman tanaman pada vertical garden di Fairmont Sanur Beach Bali dilakukan 3 bulan sekali atau situasional jika tanaman mengalami kerusakan (Gambar 10). Proses penyulaman dilakukan dengan mengganti tanaman beserta media tanamnya (Gambar 11). Tanaman yang digunakan berasal dari nursery yang dikelola oleh pihak hotel.

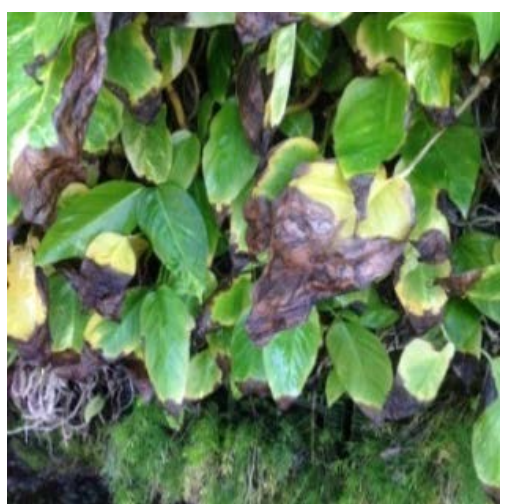

Gambar 10. Sebelum Penyulaman

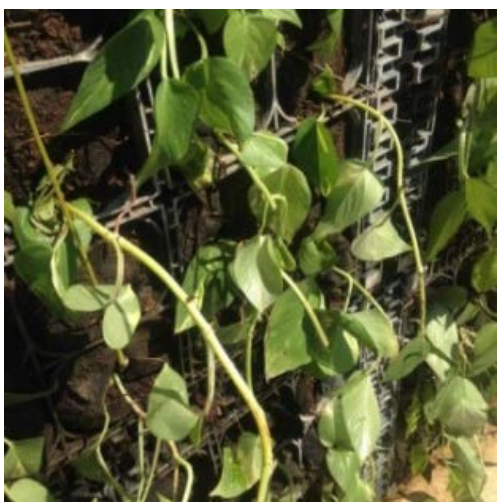

Gambar 11. Setelah Penyulaman

\subsection{Rekomendasi Jenis Tanaman Vertical Garden di Fairmont Sanur Beach Bali}

Rekomendasi jenis tanaman disusun berdasarkan syarat dan daya tumbuh yang sesuai dengan lingkungan vertical garden di Fairmont Sanur Beach Bali. Tanaman yang dipilih memiliki syarat tumbuh berupa kebutuhan cahaya penuh dan seminaungan, kebutuhan kelembapan rendah, kebutuhan penyiraman nonintensif dan semiintensif, serta kecepatan tumbuh labat dan sedang. Tanaman dengan nilai sesuai terdiri atas: Cosmos bipinnatus, Dracaena sp., Duranta sp., Euodia suaveolons, Neomarica longifolia, Justicia gendarussa, Pedilanthus tithymaloides, Aerva sanguinolenta, Cordyline sp., Rhoeo discolor, Widelia biflora, dan Pandanus pygmaeus. Sedangkan tanaman dengan nilai cukup sesuai terdiri dari: Spathoglotis plicata, Anthurium crystallinum, Euphorbia cotinifolia, Alokasia sp., Aglaonema sp, Russelia equisetiformis, Tabernaemontana corymbosa, dan Costus sp.

\section{Simpulan}

Hasil identifikasi sistem pemeliharaan vertical garden di Fairmont Sanur Beach Bali yang umum dilakukan seperti sistem penyiraman, sistem pembuangan air, pemangkasan, pemupukan, penyulaman tanaman, 
penggantian media tanam, pembersihan daun, pengendalian hama dan penyakit. Pada kegiatan pemeliharaan tersebut, penyiraman yang dilakukan selama 2 jam menciptakan kelembapan yang tinggi pada media. Hal tesebut karena volume air yang dikeluarkan tidak sepenuhnya mengalami evapotranspirasi. Sehingga media tanam tidak mengalami kekeringan pada siang hari yang mengakibatkan tanaman layu. Pada perhitungan nilai kesesuain tanaman menunjukkan nilai sesuai adalah tanaman Hemigraphis alternata. Tanaman dengan nilai cukup sesuai adalah Epipremnum aureum, Asparagus densiflorus, Ananas bracteatus tricolor, Schefflera arboricola, dan Portulaca grandiflora. Tanaman dengan nilai terendah adalah Asparagus densiflorus dibuktikan dengan kerusakan pada vertical garden.

\section{Daftar Pustaka}

Badan Meteorologi, Klimatologi, dan Geofisika. (2019). Data Curah Hujan Bulanan, Suhu Udara Rata-Rata, Kelembapan Udara, dan Lama Penyinaran Matahari Stasiun Geofisika Sanglah tahun 2009-2018.

Budiarto, S. (2013). Inspirasi Desain dan Cara Membuat Vertical Garden (T. Nixon (ed.)). AgroMedia Pustaka.

Ferniasari, R. (2011). Optimalisasi Produksi Tanaman Hias untuk Vertical Garden pada PT Godongijo Asri, Sawangan, Depok Propinsi Jawa Barat. Institut Pertanian Bogor.

Lestari, G., \& Kencana, I. P. (2015). Tanaman Hias Lanskap (F. A. Nurrohmah (ed.)). Penebar Swadaya.

Pemerintah Kota Denpasar. (2020). Peta Denpasar. https://www.denpasarkota.go.id/page/read/37. 